\title{
The Selectivity of Milking of Dunaliella salina
}

\author{
Dorinde M. M. Kleinegris • Marcel Janssen • \\ Willem A. Brandenburg • René H. Wijffels
}

Received: 22 December 2008 / Accepted: 2 May 2009/Published online: 28 May 2009

(C) The Author(s) 2009. This article is published with open access at Springerlink.com

\begin{abstract}
The process of the simultaneous production and extraction of carotenoids, milking, of Dunaliella salina was studied. We would like to know the selectivity of this process. Could all the carotenoids produced be extracted? And would it be possible to vary the profile of the produced carotenoids and, consequently, influence the type of carotenoids extracted? By using three different $D$. salina strains and three different stress conditions, we varied the profiles of the carotenoids produced. Between Dunaliella bardawil and D. salina 19/18, no remarkable differences were seen in the extraction profiles, although D. salina 19/ 18 seemed to be better extractable. D. salina 19/25 was not "milkable" at all. The milking process could only be called selective for secondary carotenoids in case gentle mixing was used. In aerated flat-panel photobioreactors, extraction was much better, but selectiveness decreased and also chlorophyll and primary carotenoids were extracted. This was possibly related to cell damage due to shear stress.
\end{abstract}

Keywords Dunaliella salina · Carotenoids · Extraction · Selectivity $\cdot$ Stress conditions

D. M. M. Kleinegris $(\bowtie) \cdot$ M. Janssen $\cdot$ R. H. Wijffels Agrotechnology and Food Science, Bioprocess Engineering Group, Wageningen University and Research Centre, P.O. Box 8129, 6700 EV Wageningen, The Netherlands e-mail: dorinde.kleinegris@wur.nl

W. A. Brandenburg

Plant Research International BV, Agrosystems Research, Wageningen University and Research Centre, P.O. Box 16, 6700 AV Wageningen, The Netherlands

\section{Introduction}

Carotenoids, a group of natural, fat-soluble, yellow to red pigments, are mainly found in plants, among which algae, and photosynthetic bacteria, where they play an important role in photosynthesis. Carotenoids protect the cell from damage by light and oxygen. Due to its capacity of accumulating large amounts of carotenoids, the alga Dunaliella salina is used worldwide as main source of natural $\beta$ carotene to meet with the increasing demand of $\beta$-carotene by food, pharmaceutical, and cosmetic industries.

Hejazi et al. (2002) developed a new method for the simultaneous production and extraction of carotenoids from D. salina. In a two-phase bioreactor, cells are cultivated under stress conditions so that they start to produce and accumulate a high quantity of carotenoids in oily globules. The carotenoids are extracted from the cells to the organic phase in a continuous process, the so-called milking of microalgae. Since mainly carotenoids are extracted and not other cell components, Hejazi et al. (2004) called the process selective. We would like to know the selectivity of this milking process. Can all the carotenoids that are produced be extracted? And is it possible to vary the profile of the produced carotenoids and, consequently, influence the kind of carotenoids extracted?

To obtain a better insight into the selectivity of the milking process, we used three strains of $D$. salina, i.e. Dunaliella bardawil, D. salina CCAP 19/18, and D. salina CCAP 19/25. D. salina CCAP 19/18 was chosen because the original milking process was based on this strain (Hejazi et al. 2002). D. bardawil, deposited at Culture Collection of Algae and Protozoa (CCAP) as D. salina CCAP 19/30, was selected because of its manifold applications by other researchers (e.g., Ben-Amotz et al. 1982). D. salina CCAP $19 / 25$ was chosen because of its 
production of relatively high amounts of zeaxanthin (Yokthongwattana et al. 2005).

Next to the use of different strains, we also varied the type of stress applied, namely, high light intensity or low temperature (with and without the combination with high light intensity). We expected these different stress factors to result in the expression of different carotenoid profiles in the cells; for example, Ben-Amotz (1996) found that, at low temperature, more 9 -cis- $\beta$-carotene is produced than alltrans- $\beta$-carotene in $D$. bardawil. The physical-chemical properties of 9-cis- $\beta$-carotene (high solubility in hydrophobic solvents and lack of crystal formation) may result in different extraction kinetics than for all-trans- $\beta$-carotene.

\section{Materials and Methods}

\section{Strain and Culture Medium}

D. bardawil was kindly provided by Dr. Ami Ben-Amotz (Nature Beta Technologies). D. salina CCAP 19/18 and D. salina CCAP 19/25 were obtained from CCAP (Oban, UK).

Stock cultures of the algae were grown in a culture medium containing $1.00 \mathrm{M} \mathrm{NaCl}, 9.95 \times 10^{-4} \mathrm{M} \mathrm{Na}_{2} \mathrm{H}_{2}$ $\mathrm{PO}_{4} \cdot 2 \mathrm{H}_{2} \mathrm{O}, 3.78 \times 10^{-2} \mathrm{M} \mathrm{KNO}_{3}, 2.25 \times 10^{-2} \mathrm{M} \mathrm{Na}_{2} \mathrm{SO}_{4}$, $1.00 \times 10^{-2} \mathrm{M} \mathrm{NaHCO}_{3}, 4.87 \times 10^{-3} \mathrm{M} \mathrm{K}_{2} \mathrm{SO}_{4}, 3.68 \times 10^{-4}$ $\mathrm{M} \mathrm{MgCl}_{2} \cdot 6 \mathrm{H}_{2} \mathrm{O}, 1.89 \times 10^{-5} \mathrm{M} \mathrm{CaCl}_{2} \cdot 2 \mathrm{H}_{2} \mathrm{O}$, and $1.13 \times 10^{-5}$ $\mathrm{M}$ FeEDTA. In addition, the medium contained micronutrients: $1.94 \times 10^{-5} \mathrm{M} \mathrm{Na} \mathrm{NaDTA}_{2} \cdot 2 \mathrm{H}_{2} \mathrm{O}, 1.89 \times 10^{-6} \mathrm{M}$ $\mathrm{MnCl}_{2}, 1.48 \times 10^{-6} \mathrm{M} \mathrm{ZnSO}_{4}, 6.65 \times 10^{-7} \mathrm{M} \mathrm{CuSO}_{4}, 1.10 \times$ $10^{-8} \mathrm{M} \mathrm{Na}_{2} \mathrm{MoO}_{4}$, and $9.95 \times 10^{-9} \mathrm{M} \mathrm{CoCl}_{2}$. The solution was buffered with $4.00 \times 10^{-2} \mathrm{M}$ HEPES acid and adjusted to $\mathrm{pH} 7.5$ with $3 \mathrm{M} \mathrm{NaOH}$.

The medium was sterilized at $121^{\circ} \mathrm{C}$ for $30 \mathrm{~min}$. The phosphate, magnesium, calcium, and carbonate salts were separately sterilized and added after autoclaving to avoid precipitation.

All strains were maintained as suspended culture in $250 \mathrm{~mL}$ Erlenmeyer flasks containing $100 \mathrm{~mL}$ of medium. Cultures were kept in a growth cabinet at $25^{\circ} \mathrm{C}$ under continuous light with an intensity of $120-150 \mu \mathrm{mol} \cdot \mathrm{m}^{-2} \cdot \mathrm{s}^{-1}$ and were continuously shaken. The headspace consisted of an air $/ \mathrm{CO}_{2}$ ratio of $95 / 5 \%$. Every week, $10 \mathrm{~mL}$ of a culture was transferred to a new flask containing fresh medium.

\section{Cultivation Systems}

The first set of extraction experiments was carried out in 1-L glass bottles containing $300 \mathrm{~mL}$ of culture medium (as described above, but without the addition of HEPES buffer). The bottles (diameter $9 \mathrm{~cm}$ ) were equipped with two magnetic stirrers fixed on one axis, stirring at a rate of
$110 \mathrm{rpm}$. The lower stirrer (diameter $6.0 \mathrm{~cm}$, width $1.0 \mathrm{~cm}$ ) was placed $0.5 \mathrm{~cm}$ from the bottom and the upper one (sixbladed turbine stirrer, diameter $3 \mathrm{~cm}$, paddle width and height $0.5 \mathrm{~cm}$ ) was placed at the surface of the cell suspension (liquid height $6 \mathrm{~cm}$ ). The $\mathrm{pH}$ was continuously measured and adjusted by giving short pulses of carbon dioxide to the reactors. The bottles were illuminated from the bottom side with fluorescent lamps (Sylvania CF-EL $55 \mathrm{~W} / 840)$ with an average light intensity of $109 \pm$ $10 \mu \mathrm{mol} \cdot \mathrm{m}^{-2} \cdot \mathrm{s}^{-1}$ for the growth period. During light stress, light intensity was increased to $800 \pm 67 \mu \mathrm{mol} \cdot \mathrm{m}^{-2} \cdot \mathrm{s}^{-1}$ from the bottom and an extra light source (slide projector with halogen lamp) was placed at the side of the reactor to reach higher light intensities $\left(1,899 \pm 708 \mu \mathrm{mol} \cdot \mathrm{m}^{-2} \cdot \mathrm{s}^{-1}\right.$ additional illumination from one side). The bottles were placed in a large water bath to regulate temperature at $25.0 \pm 0.3^{\circ} \mathrm{C}$ for the growth period and light stress and $16.5 \pm 1.5^{\circ} \mathrm{C}$ for cold stress.

The second set of extraction experiments was carried out in flat-panel FMT150 photobioreactors (PSI, Brno, Czech Republic). These panel bioreactors have a width of $10 \mathrm{~cm}$, depth of $2.5 \mathrm{~cm}$, and height of $19 \mathrm{~cm}$ containing $300 \mathrm{~mL}$ of culture medium (as described above, but without the addition of HEPES buffer). Cell suspension was stirred by aeration $(0.3 \mathrm{~L} / \mathrm{min})$. The $\mathrm{pH}$ was online-measured and continuously adjusted by giving short pulses of carbon dioxide to the reactors. The bottles were illuminated from one side with light-emitting diodes (red, $627 \mathrm{~nm}$ and blue, $455 \mathrm{~nm}$ ) with an average light intensity of $100 \pm$ $1 \mu \mathrm{mol} \cdot \mathrm{m}^{-2} \cdot \mathrm{s}^{-1}$ for the growth period. During light stress, light intensity was increased to $1,700 \pm 22 \mu \mathrm{mol} \cdot \mathrm{m}^{-2} \cdot \mathrm{s}^{-1}$. Temperature was regulated via a Peltier element, directly cooling the bottom side of the bioreactor. Temperature was maintained at $25.0 \pm 0.1{ }^{\circ} \mathrm{C}$ for the growth period and for the cold stress: D. bardawil at $14.0 \pm 0.1^{\circ} \mathrm{C}$ and D. salina $19 / 18$ at $17.0 \pm 0.1^{\circ} \mathrm{C}$.

Reactors were inoculated with a 1-week-old stock culture to a concentration of approximately $7 \times 10^{5}$ cells per milliliter. When a cell number of more than $1 \times 10^{6}$ cells per milliliter was reached in the reactor, stress conditions were applied. Per strain, seven cultivations were performed. One control without stress or dodecane, two with light stress, two with cold stress, and two with light and cold stress (for each stress, one with and one without dodecane). In the first set of experiments, dodecane $(75 \mathrm{~mL})$ was added to milk the cells from the start of stress. Dodecane was gently mixed with the aqueous phase by means of the upper stirrer, as described before. The dodecane layer was shielded from illumination from the side by an aluminum foil cover around the reactor.

In the second set of experiments, the dodecane could not be added at the same time as stress was induced. The aeration caused the dodecane layer to emulsify and spread 
through the whole reactor. Consequently, the dodecane with extracted carotenoids would be in the illuminated zone and extracted carotenoids could be broken down, which would influence our results. To overcome this problem, dodecane was added at the end of the experiment, after lights were shut off. Emulsification still appeared, but carotenoids were no longer exposed to light. Time was limited to $2 \mathrm{~h}$, to prevent the cells from overgrowing stress, since cells were no longer light-stressed.

For the first set of experiments, we made use of all three algae strains, D. bardawil, D. salina $19 / 18$, and D. salina $19 / 25$. For the second set of experiments, we only made use of D. bardawil and D. salina 19/18. D. salina $19 / 25$ was left out because the first set of experiments already showed that milking this strain did not give good results.

\section{Analytical Procedures}

Cell growth and stress were regularly followed during cultivation by optical density measurements at 530 and $680 \mathrm{~nm}$ on a spectrophotometer (Spectronic ${ }^{\circledR} 20$ Genesys, Spectronic Instruments, UK), measured against a reference of demineralized water. Cell number and volume were measured with a Beckman Coulter Multisizer $3(100 \mu \mathrm{m}$ orifice; Beckman Coulter, Fullerton, CA, USA). The diameter of the cells was calculated from their volume.

The dry weight of the cell suspension was determined at the end of the cultivation, as described by Zhu and Lee (1997) with adaptations as described. Five milliliters of cell suspension was washed three times with $25 \mathrm{~mL}$ ammonium formate $(1 \mathrm{M})$ over a predried and weighed filter (precombusted $\left[450^{\circ} \mathrm{C}, 2 \mathrm{~h}\right]$ glass fiber filter, Whatman $\mathrm{GF} / \mathrm{F}$, retention size $0.7 \mu \mathrm{m})$. Filters were dried in an oven for $24 \mathrm{~h}\left(98^{\circ} \mathrm{C}\right)$, allowed to cool down in a dessicator for at least $2 \mathrm{~h}$, and reweighed. Measurements were performed in triplicate.

\section{Pigment Analysis}

Samples were taken at the end of the stress period. Five milliliters of cell suspension was centrifuged for $10 \mathrm{~min}$ at $2,500 \mathrm{rpm}$ and at $4^{\circ} \mathrm{C}$. The dodecane was divided over freeze-drying flasks $\left(10 \mathrm{~mL}\right.$ per flask) and stored at $-80^{\circ} \mathrm{C}$. All dodecane samples were freeze-dried after the last run of each set-up. Freeze-drying was performed in a Christ Epsilon 2-60 freeze-dryer (Salmenkipp, Breukelen, The Netherlands) to obtain a pellet of the extracted substances. Frozen dodecane samples were transferred from $-80^{\circ} \mathrm{C}$ to the precooled freeze-dryer $\left(-20^{\circ} \mathrm{C}\right)$. Next, vacuum was started (1.03 mbar) and the samples were freeze-dried for $20 \mathrm{~h}$ at $-20^{\circ} \mathrm{C}$. After this, a second drying step was performed at $-10^{\circ} \mathrm{C}$ for at least another $20 \mathrm{~h}$ and at $0.001 \mathrm{mbar}$. After all dodecane was evaporated, the flasks containing pellets were again transferred to a freezer $\left(-80^{\circ} \mathrm{C}\right)$ awaiting the next steps of pigment analysis.

The extraction of lipids was performed according to the method of Fraser et al. (2000) with adaptations described. Whenever possible, all manipulations were carried out on ice and shielded from strong light. For the extraction of lipids, $4 \mathrm{~mL}$ of methanol/chloroform (2.5:2, including $0.1 \%$ butylated hydroxytoluene [BHT]) was added to the tubes, which contained pellets of approximately 1-5 mg dry weight (cell suspension) or remaining pellets of $10 \mathrm{~mL}$ freeze-dried dodecane. The suspension was mixed and incubated for $10 \mathrm{~min}$ in a sonicator bath. Tris $-\mathrm{HCl} / \mathrm{NaCl}$ solution $(2.5 \mathrm{~mL} ; 50 \mathrm{mM}$ Tris- $\mathrm{HCl}, 1 \mathrm{M} \mathrm{NaCl} ; \mathrm{pH}$ 7.5) was added to the suspension, mixed, and incubated for $10 \mathrm{~min}$ in a sonicator bath. To obtain a clear phase separation, the tubes were centrifuged for $10 \mathrm{~min}$ at 2,500 rpm. The lower phase (chloroform) was transferred to a new clean tube. To the remaining phase, $1 \mathrm{~mL}$ of chloroform (including $0.1 \%$ BHT) was added for further extraction. The suspension was mixed, incubated for $10 \mathrm{~min}$ in a sonicator bath, and centrifuged for $10 \mathrm{~min}$ at $2,500 \mathrm{rpm}$. The lower phase was pooled with the previous chloroform phase. This extraction step was repeated two more times. The pooled chloroform extracts were dried by flushing with nitrogen gas. The dried residues were dissolved in ethylacetate (including $0.1 \%$ BHT) to prepare them for high-performance liquid chromatography (HPLC) analysis. To remove the remaining impurities, samples were incubated in the sonicator bath for $10 \mathrm{~min}$ and centrifuged for $10 \mathrm{~min}$ at 2,500 rpm. For the analysis, dark glass HPLC bottles were used. HPLC with photodiode array analysis was performed as described by Bino et al. (2005). The first set-up experiments were performed and analyzed separately from the second set of experiments with the flat-panel reactors. During the first HPLC run, the neoxanthin peak was separated from the violaxanthin peak. During the second run, the neoxanthin and violaxanthin peaks were inseparable. Here, the total surface of the combined peak of neoxanthin/ violaxanthin was determined and used as if one peak.

\section{Results and Discussion}

The so-called milking of microalgae has proved to be a good method for the production of carotenoids by $D$. salina. This process was called selective since mainly carotenoids are extracted (Hejazi et al. 2004). By using three algae strains and three different types of stress, we expected expression of varying carotenoid profiles by the algae and, consequently, varying profiles of carotenoids extracted through milking. In this way, we would like to obtain insight into the selectivity and controllability of the milking process of $D$. salina. 
In Fig. 1, cell number, optical density, and cell diameter of $D$. bardawil are shown during the growth period and the subsequent stress periods with high light intensity (Fig. 1a), low temperature (Fig. 1b), and the combination of high light intensity and low temperature (Fig. 1c). D. salina 19/18 and D. salina 19/25 gave similar results (not shown here).
As can be seen, the cells were in a lag-phase for the first $12 \mathrm{~h}$. Cell diameter increased, as the cells experienced their transfer from the Erlenmeyer bottle to the reactor as stressful. Hereafter, they started dividing. After cell numbers of approximately $1 \times 10^{6}$ cells per milliliter were reached, stress was started. High light intensity resulted in
Fig. 1 Growth curves of $D$. bardawil during cultivation and stress with a hight light intensity, $\mathbf{b}$ low temperature, and $\mathbf{c}$ the combination of high light intensity and low temperature. Dashed lines indicate start stress. Error bars represent the standard deviation, $n=2$
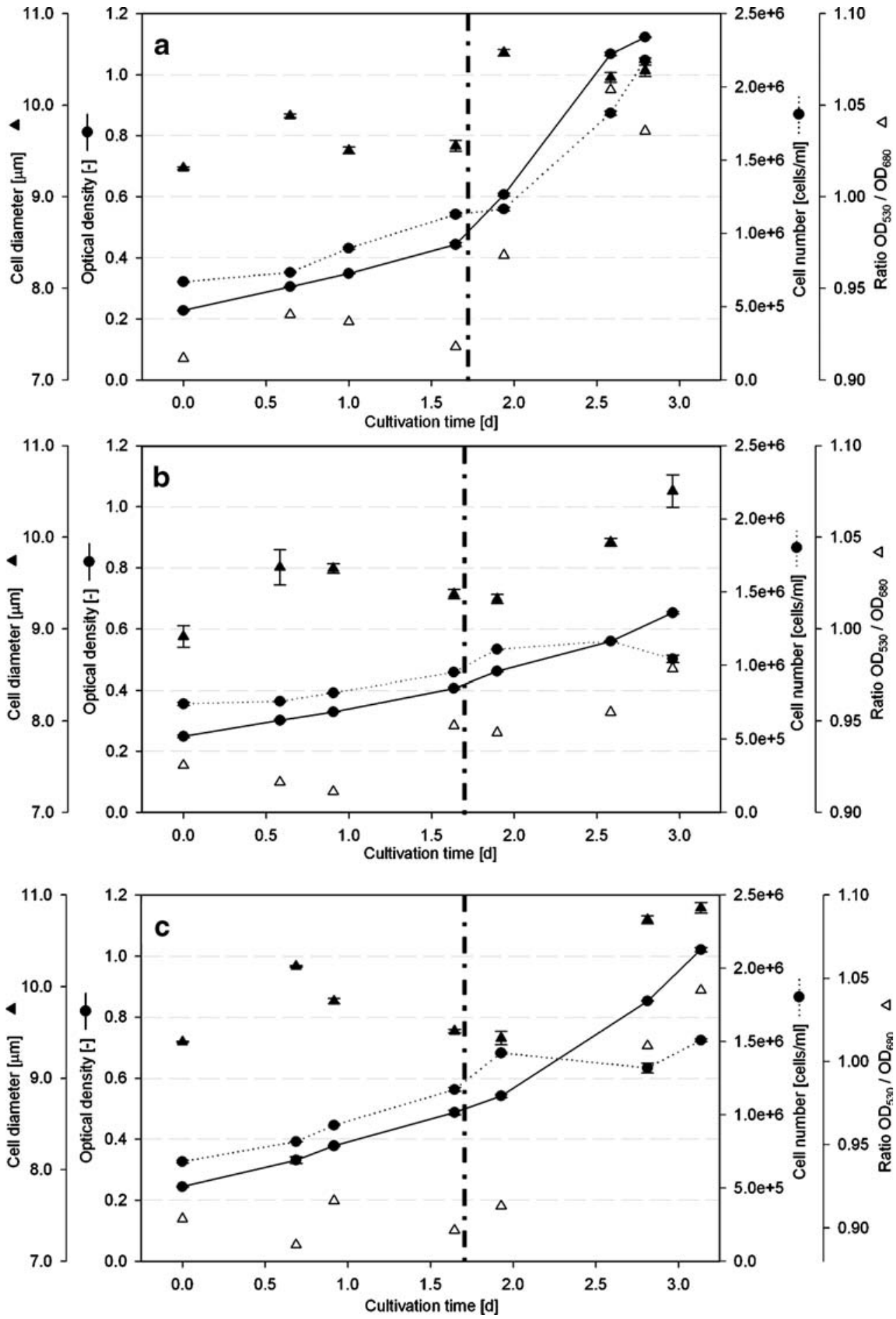
an increase in cell diameter. The first-hour stress was severe enough to be growth limiting and cell numbers were kept constant. After these first hours, the cells started to overgrow the stress and cell numbers increased again. However, cell diameter remained high and the ratio of the optical density at $530 \mathrm{~nm}$ over the optical density at $680 \mathrm{~nm}$ $\left(\mathrm{OD}_{530} / \mathrm{OD}_{680}\right)$ increased, indicating stress-related carotenoid production.

The curves for low temperature stress and the combination of high light and low temperature stress show a similar profile, though cells were less capable of overgrowing the stress implied.

Production of Carotenoids

\section{D. bardawil/D. salina 19/18}

The profiles of the carotenoids produced by $D$. bardawil and $D$. salina $19 / 18$ were quite similar for each stress variant (Fig. 2a, b). The presence of dodecane did not
Fig. 2 a Carotenoids produced by $D$. bardawil under stress conditions: no stress, $H L$ high light intensity, $L T$ low temperature, $H L / L T$ combination of high light intensity and low temperature. Error bars represent the $95 \%$ confidence interval. b Carotenoids produced by $D$. salina 19/18 under stress conditions: no stress, $H L$ high light intensity, $L T$ low temperature, $H L / L T$ combination of high light intensity and low temperature. Error bars represent the $95 \%$ confidence interval. c Carotenoids produced by $D$. salina 19/25 under stress conditions: no stress, $H L$ high light intensity, $L T$ low temperature, $H L / L T$ combination of high light intensity and low temperature. Error bars represent the $95 \%$ confidence interval

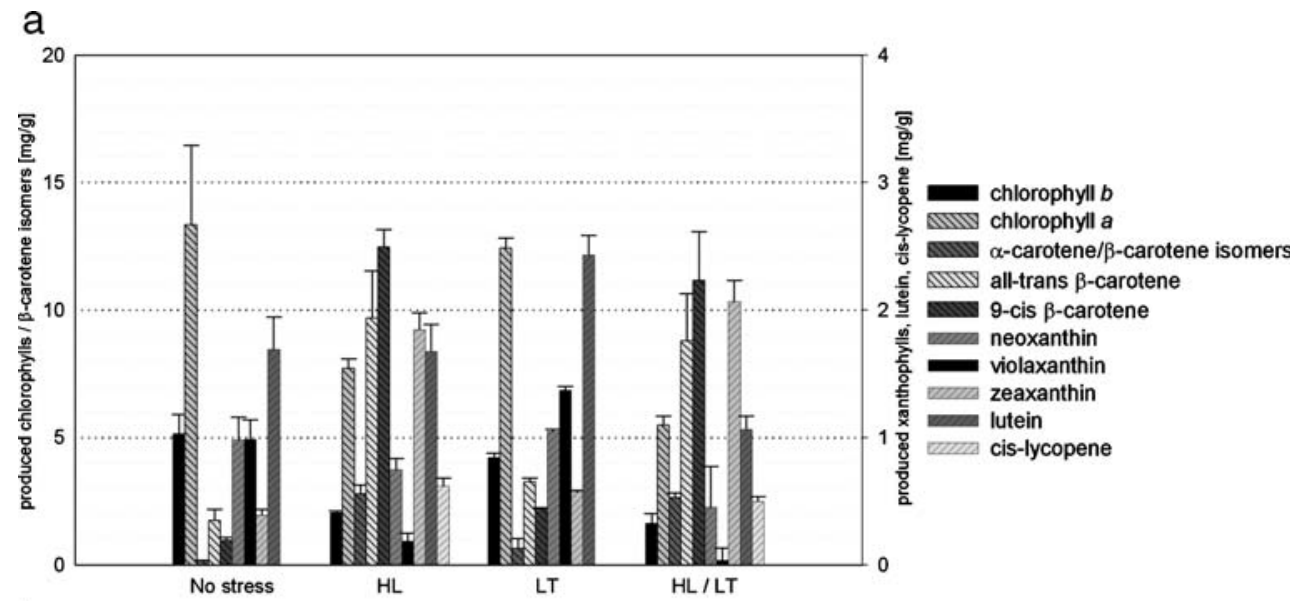

b

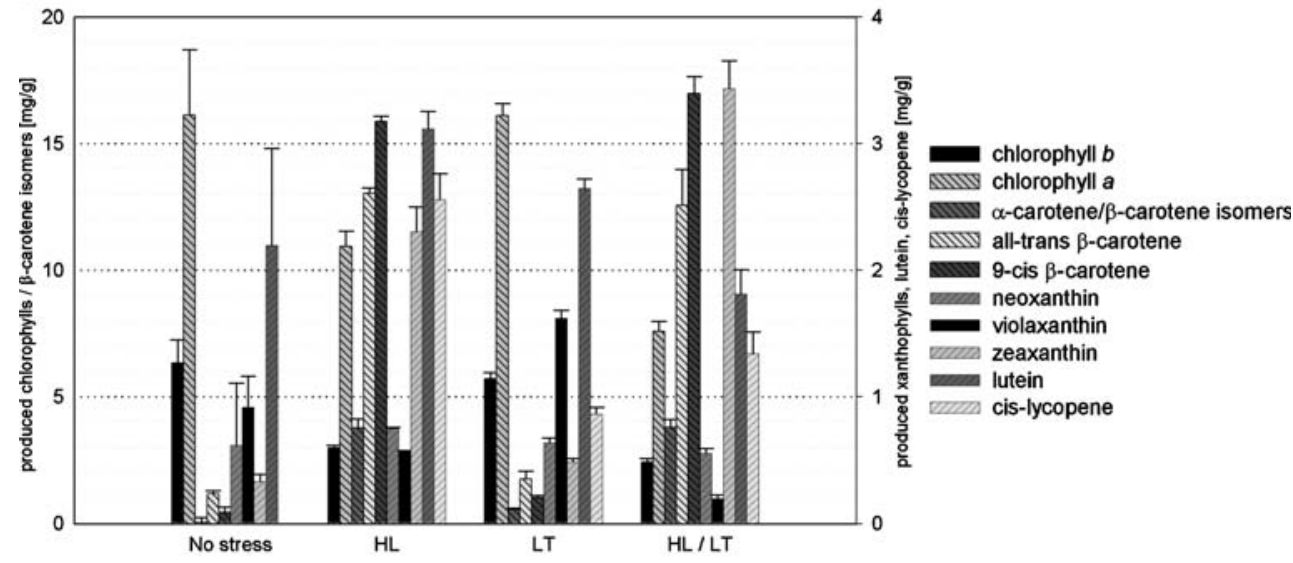

C

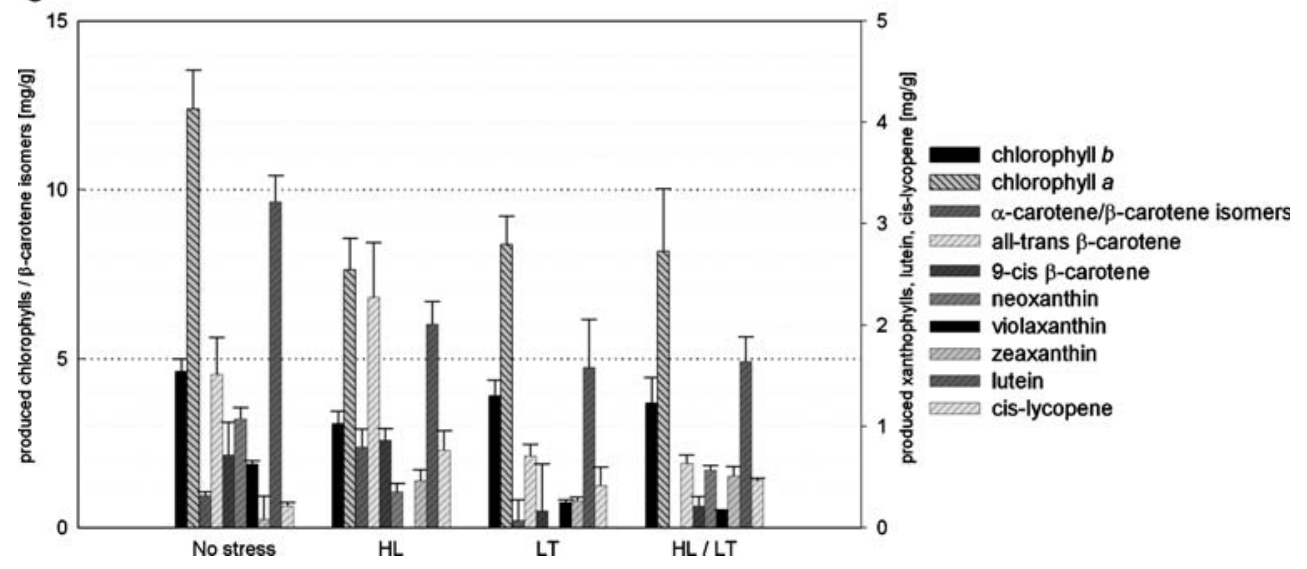


influence carotenoid production. Therefore, these results are not shown.

Chlorophyll levels and the carotenoids neoxanthin, violaxanthin, and lutein were produced in lesser amounts or remained constant in comparison to cells grown without stress.

At high light intensities, the de-epoxidation reaction in the violaxanthin reaction will take the upper hand and violaxanthin will be converted to antheraxanthin and, subsequently, zeaxanthin, which will be accumulated in the chloroplast thylakoids (Jin et al. 2002; Yamamoto 1979). This is in agreement with our results when high light intensities were used for stress. The xanthophylls neoxanthin and violaxanthin decreased with high light intensity and a sharp increase in zeaxanthin was seen.

However, in case of low temperatures used for stressing, concentrations of all xanthophylls remained approximately constant. This does not coincide with the suggestion that cold stress can be seen as light stress, assuming that the stress inflicted is not about the irradiance intensity itself, but about the amount of photons that are received per cell division time (Ben-Amotz and Avron 1983; Krol et al. 1997).

All three stress conditions resulted mainly in the production of extra $\beta$-carotene in its various isomers and, in some cases, in the accumulation of zeaxanthin and cislycopene. In case of light stress, the $\beta$-carotene/chlorophyll ratio increased from 0.16 to 2.56 for $D$. bardawil and from 0.07 to 2.35 for $D$. salina $19 / 18$. For low temperature, this effect was less pronounced, but still, the ratio $\beta$-carotene/ chlorophyll increased from 0.16 to 0.37 for $D$. bardawil and from 0.07 to 0.15 for $D$. salina $19 / 18$. The combination of light stress and low temperature resulted in an increase of the $\beta$-carotene/chlorophyll ratio to 3.19 for $D$. bardawil and to 3.33 for D. salina $19 / 18$.

In case high light intensity was used to stress the cells, the ratio of 9-cis/all-trans $\beta$-carotene increased from 0.55 to 1.27. For stress by low temperature, this effect was less obvious, but still apparent ( 0.55 to 0.67 ).

The results obtained in this study are quite comparable to the literature. For example, several researchers found that the ratio of 9-cis to all-trans $\beta$-carotene increased when cells were stressed (Ben-Amotz 1996; Ben-Amotz et al. 1988; Garcia-Gonzalez et al. 2005). Jimenez and Pick (1994) found that this increase in 9-cis to all-trans $\beta$ carotene ratio was mainly due to an accumulation of carotenoid-containing globules and a decrease in thylakoid-bound carotenoids. The globules contained over $50 \%$ 9-cis $\beta$-carotene, whereas the thylakoids contained mainly all-trans $\beta$-carotene. However, in some cases, literature is contradictory concerning the production of certain carotenoids in reaction to certain stress conditions. For example, Garcia-Gonzalez et al. (2005) and Krol et al. (1997) found that lutein levels increased with both light stress and cold stress. However, Ben-Amotz et al. (1988) and Leon et al. (2003) found that levels decreased when cells were stressed with light stress or nitrogen starvation, respectively. We found that lutein levels remained quite constant or decreased slightly with light stress involved and seem to increase slightly when cells were stressed by low temperature.

A more detailed overview on why cells start to produce certain carotenoids under stress conditions and what regulatory mechanisms concerning carotenogenesis are understood so far is given by Lamers et al. (2008).

\section{D. salina $19 / 25$}

D. salina $19 / 25$ clearly showed a very different carotenoid profile compared to D. bardawil and D. salina 19/18. D. salina 19/25 produced only very low amounts of carotenoids (Fig. 2c). Yokthongwattana et al. (2005) measured approximately $1.1 \mathrm{pg}$ carotenoids per cell, whereas in this study, we found $1.4 \mathrm{pg}$ carotenoids per cell.

The amount of chlorophyll and primary carotenoids neoxanthin, violaxanthin, and lutein decreased per gram biomass when cells were stressed, independent of the type of stress invoked. Light stress resulted in an increase of the carotenoids $\beta$-carotene, zeaxanthin, and cis-lycopene. In case temperature stress was involved, amounts of $\beta$ carotene decreased as well and only zeaxanthin and cislycopene were accumulated.

Previous research showed that both chlorophyll and carotenoid content decreased per cell after light stress (Yokthongwattana et al. 2005). This carotenoid decrease accounted for all determined carotenoids (neoxanthin, violaxanthin, antheraxanthin, lutein, and $\beta$-carotene), except for zeaxanthin where an increase was found from 0.25 to $2.0 \mathrm{pg}$ per cell. In this research, an increase in zeaxanthin for light stress was found from 0.02 to $0.08 \mathrm{pg}$ per cell. This is little less than found by Jin and Melis (2003), who found that light-stressed cells of D. salina 19/25 produced $0.22 \mathrm{pg}$ zeaxanthin per cell, also an almost eightfold increase compared to nonstressed cells $(0.03 \mathrm{pg}$ zeaxanthin per cell).

\section{Extraction}

The profile of the extracted carotenoids was as expected. Mostly, $\beta$-carotene (various isomers) was extracted and next to that zeaxanthin, cis-lycopene, and lutein (Fig. 3). These are secondary carotenoids that are not only coupled to the photosystem in the thylakoid membranes to help with photosynthesis but moreover they are extra produced in large quantities under stress conditions and function as protective layer against stress. Secondary carotenoids are characterized by their localization in extraplastidic globules 
Fig. 3 Extracted carotenoids and chlorophylls as the percentage produced either by $D$. bardawil, D. salina $19 / 18$, or $D$. salina 19/25; (db) D. bardawil, (19/18) D. salina 19/18, (19/25) D. salina $19 / 25$. Stress by $L$ high light intensity, $T$ low temperature, or $L T$ combination of high light intensity and low temperature. Error bars represent the standard deviation, $n=3$

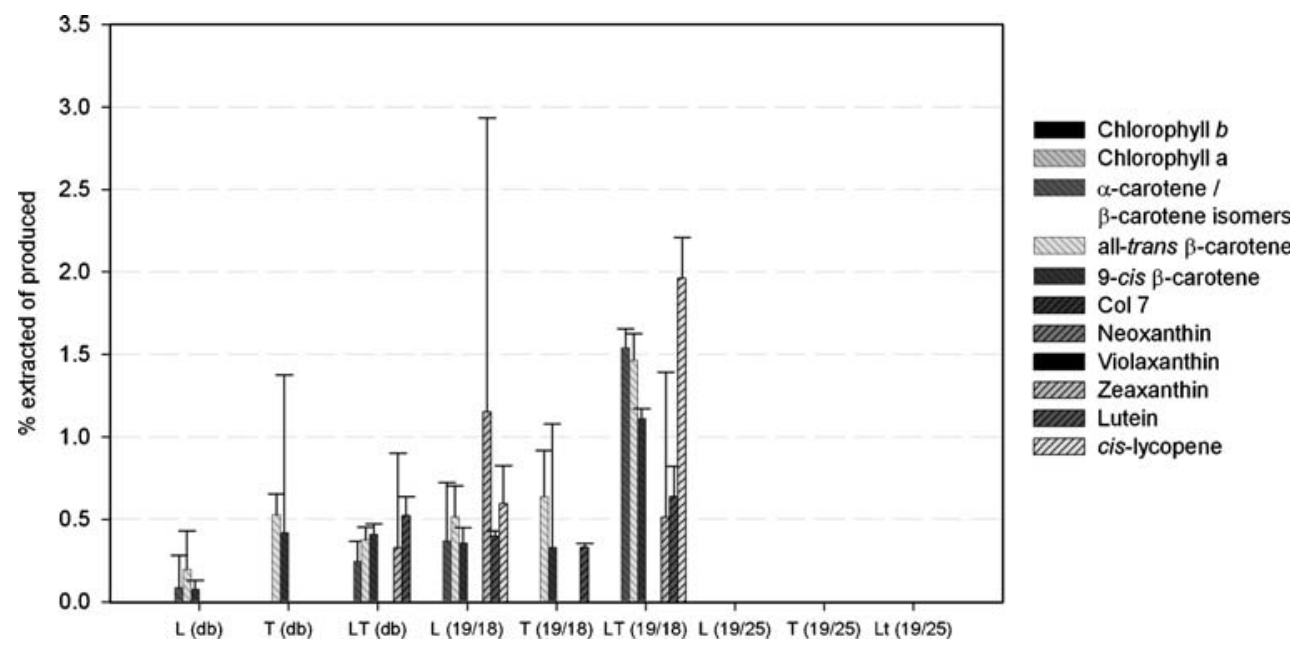

(Skulberg 2004). These globules consist mainly of neutral lipids of which $30 \%$ is carotenoids and less than $3 \%$ is chlorophyll. The carotenoids in these globules exist mainly as $\beta$-carotene in the form of 9-cis and all-trans $\beta$-carotene. Further small amounts of 15-cis, some unidentified other isomers of $\beta$-carotene, and $\alpha$-carotene were described (Ben-Amotz et al. 1982; Jimenez and Pick 1994).

The fact that we find approximately equal amounts of 9-cis and all-trans $\beta$-carotene as extracted carotenoids and some other $\beta$-carotene isomers (among which also probably $\alpha$-carotene) feeds the idea that the carotenoids accumulated in globules that are extracted during milking.

Also, zeaxanthin, lutein, and cis-lycopene were found among the extracted carotenoids. Thus far, it has not been reported that these three carotenoids consisted in carotenoid-containing globules in D. bardawil. However, various researchers (Yokthongwattana et al. 2005; Bassi and Caffarri 2000; Bassi et al. 1993; Jin et al. 2001; Tardy and Havaux 1996) found that the zeaxanthin and lutein that D. salina formed in excess during stress is not bound to chlorophyll proteins in the thylakoid membrane as in low light grown cells. Yet, this excess zeaxanthin and lutein is located in the lipid bilayer or at least somewhere in the chloroplast thylakoids where it can be easily separated from the chlorophyll. Extraction of lutein is previously found by others as well in their two-phase cultivation system of $D$. bardawil (Leon et al. 2003).

In some cases, not all secondary carotenoids were extracted; this could be due to the very low amounts produced and, consequently, even lower-undetectableamounts of carotenoids extracted. No carotenoids were extracted during the milking of $D$. salina $19 / 25$ (Fig. 2). It is not clear whether this is caused by the very low amounts of carotenoids produced or whether cells of D. salina 19/25 are not extractable via the milking process.

Only low percentages of carotenoids were extracted when milking was performed in the stirred reactors (Fig. 3).
Though the amounts of carotenoids produced for $D$. bardawil and D. salina 19/18 were approximately the same, the amounts of extracted carotenoids were little higher for D. salina 19/18.

We produced maximally $10 \mathrm{mg}$ carotenoids per reactor in case of D. salina $19 / 18$ and the stress combination of high light intensity and low temperature, which corresponds with approximately $33 \mathrm{mg} / \mathrm{L}$ culture. In the dodecane phase, we extracted approximately $0.1 \mathrm{mg} / \mathrm{L}$, which corresponds to approximately $1 \%$ of the total carotenoids, the maximum value found in this research. In the research performed by Hejazi et al. (2003) in the same set-up, similar results were found for the same time span.

The low extraction percentages can be explained by (1) the fact that we only stressed and milked the cells for $48 \mathrm{~h}$ and (2) the fact that we used simple systems that were stirred gently by magnetic stirrer bars, resulting in a small surface contact between the dodecane and the cell suspension. The extraction percentages can be improved by increasing the extraction time and, more importantly, by increasing the contact area between the dodecane and the biomass.

This is shown in the research performed by Hejazi et al. (2002) where values of $12 \mathrm{mg}$ carotenoids/L culture and approximately $2 \mathrm{mg}$ carotenoids/L dodecane were obtained. In these experiments, Hejazi and coworkers made use of flat-panel photobioreactors in which the mixing was performed by recirculation of the dodecane itself through the aqueous phase. This resulted in an increased contact between cells and organic phase. Elsewhere, approximately $8 \%$ of the total carotenoids were extracted after 4 days of stressing and milking (Leon et al. 2003).

Therefore, we also used a second set-up in which we performed almost the same experiments as in the first setup. Only, in this set-up, we used small flat-panel photobioreactors, stirred by aeration. We chose not to recirculate the dodecane to prevent carotenoid degradation by light. 
Table 1 Extraction values for both reactor set-ups

\begin{tabular}{|c|c|c|c|c|}
\hline Set-up & Cells & Stress & $\begin{array}{l}\text { Carotenoids produced } \\
\text { [percent of biomass] }\end{array}$ & $\begin{array}{l}\text { Carotenoids extracted } \\
\text { [percent of produced] }\end{array}$ \\
\hline \multirow[t]{9}{*}{ Stirred reactor } & \multirow[t]{3}{*}{ D. bardawil } & HL & 3.0 & 0.1 \\
\hline & & LT & 1.2 & 0.1 \\
\hline & & HL/LT & 2.7 & 0.3 \\
\hline & \multirow[t]{3}{*}{ D. salina $19 / 18$} & $\mathrm{HL}$ & 4.2 & 0.3 \\
\hline & & LT & 1.0 & 0.1 \\
\hline & & HL/LT & 4.1 & 1.0 \\
\hline & \multirow[t]{3}{*}{ D. salina $19 / 25$} & $\mathrm{HL}$ & 0.8 & 0 \\
\hline & & LT & 0.3 & 0 \\
\hline & & $\mathrm{HL} / \mathrm{LT}$ & 0.4 & 0 \\
\hline \multirow[t]{6}{*}{ Aerated reactor } & \multirow[t]{3}{*}{ D. bardawil } & $\mathrm{HL}$ & 6.1 & 2.4 \\
\hline & & LT & 1.7 & 3.5 \\
\hline & & $\mathrm{HL} / \mathrm{LT}$ & 4.4 & 3.6 \\
\hline & \multirow[t]{3}{*}{ D. salina $19 / 18$} & $\mathrm{HL}$ & 1.0 & 1.0 \\
\hline & & LT & 1.5 & 5.3 \\
\hline & & $\mathrm{HL} / \mathrm{LT}$ & 0.4 & 1.9 \\
\hline
\end{tabular}

Two algal strains were used (D. bardawil and D. salina 19/ 18), again with three stress variants: high light intensity, low temperature, and the combination of both. The time used for stressing was equal to the time used in the first setup, but the extraction time was shortened to $2 \mathrm{~h}$. Extraction was done with aeration but whitout illumination. With these reactors, much higher extraction values than in the first setup were reached (Table 1). These values are comparable to the aforementioned values of Hejazi et al. (2004) and Leon et al. (2003).

As can be seen in Fig. 4, in this set-up, chlorophylls were also extracted, mainly chlorophyll- $a$, but also neoxanthin/violaxanthin (in this HPLC run, the peaks of neoxanthin and violaxanthin overlap, so we measured the combined peak). Hejazi et al. (2003) also found low amounts of chlorophyll to be extracted (up to $3 \%$ of the total amount of chlorophyll). It is not known whether this extracted chlorophyll is the result of cell death due to the more vigorous stirring (Hejazi found that cell death was up to $10 \%$ in his set-up) or whether chlorophyll can be milked from the cells as well. Ben-Amotz et al. (1982) found low amounts of chlorophyll in the separated globules. Chlorophyll is heterogenically bound to other compounds in the chloroplast with mainly strong hydrophilic bonds. However, Deroche and Briantais (1974) and Öquist and Samuelsson (1980) report that there exist some forms of chlorophyll- $a$ that are loosely bound in the cell. The fact that chlorophyll is very lipophillic and has a $\log P$ value similar to the $\log P$ value of $\beta$-carotene (chlorophyll 17.2, $\beta$-carotene 17.6) makes this chlorophyll- $a$ a plausible
Fig. 4 Extracted carotenoids and chlorophylls as percentage produced either by $D$. bardawil or D. salina 19/18; (db) D. bardawil, (19/18) D. salina $19 / 18$. Stress by $L$ high light intensity, $T$ low temperature, or $L T$ combination of high light intensity and low temperature. Error bars represent the standard deviation, $n=3$

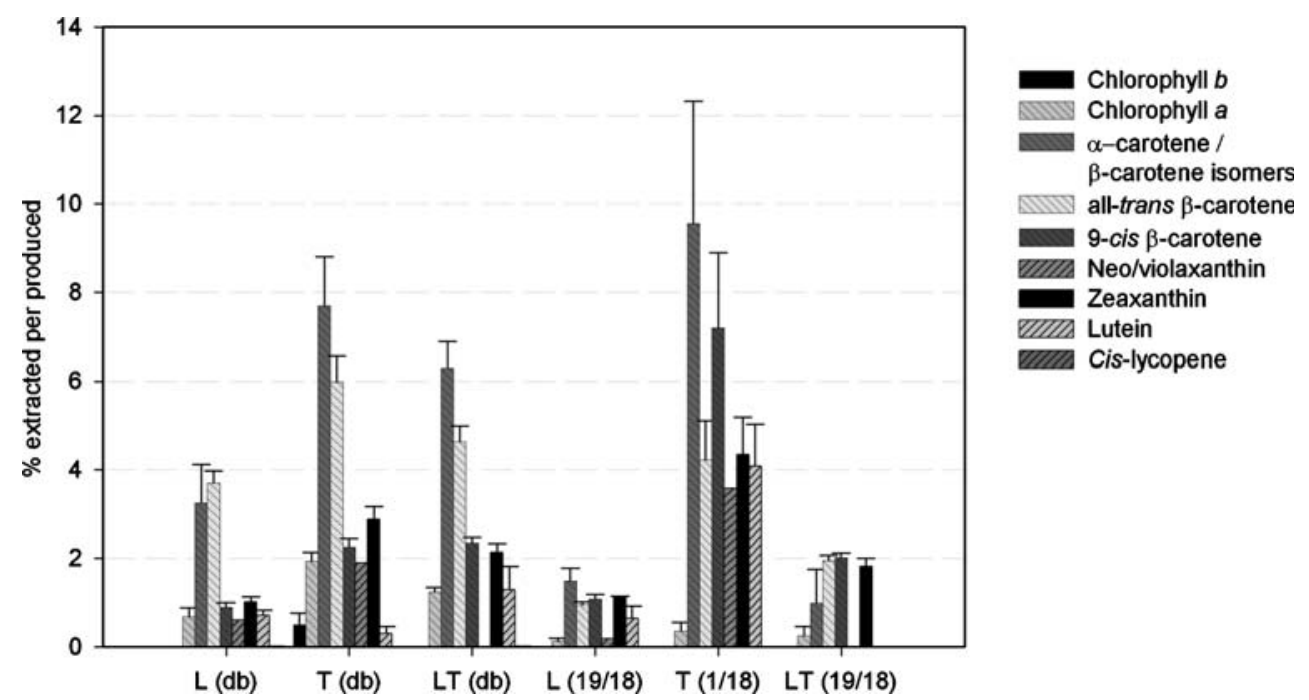


candidate for extraction. However, the fact that chlorophyll$b$, neoxanthin, and violaxanthin were extracted in some cases as well suggests cell death as reason for extraction.

In this research, our main objective was to compare the produced carotenoid profile with the extracted carotenoids and see whether all produced carotenoids could be milked. In the first set-up with low extraction percentages, all extraproduced secondary carotenoids were extracted. In the second set-up, much higher extraction percentages were obtained, but next to that, the extraction was not purely selective for secondary carotenoids. Also, chlorophyll was extracted due to cell death. This cell death was most probably caused by shear as a result of aeration.

In our opinion, a most optimal milking process in the future circumvents cell death by shear (caused by, e.g., aeration or agitated mixing), but at the same time creates a large contact area between the organic phase and the biomass. Also, the dodecane (containing extracted carotenoids) should be prevented from being illuminated, to prevent light-induced carotenoid degradation. If all these important considerations are taken into account, we think that milking is a powerful tool to obtain secondary carotenoids from $D$. salina in a constant process.

\section{Conclusions}

Our first aim to produce different carotenoid profiles with three strains was successfully obtained. The extraction profiles, however, were quite similar for all circumstances. Mainly, secondary carotenoids were extracted. Only the amounts varied for the different strains. The highest amounts of carotenoids were extracted from D. salina 19/ 18. D. salina $19 / 25$ seemed not to be a suitable strain for milking, since no carotenoids were extracted.

In a second set-up with more vigorous stirring, chlorophylls and primary carotenoids were also extracted next to secondary carotenoids. Thus, milking decreased in selectivity. Our results suggest that chlorophylls and primary carotenoids were extracted from cells that were killed due to shear stress because of the vigorous aeration. If one is only interested in high extraction rates and not too much in the selectivity of the process and whether (small) amounts of chlorophyll are milked as well, it is better to create a large surface between cell suspension and the organic phase, for example, by vigorous aeration. This results in a much higher extraction rate than when gently stirred. At low stirring rates, the milking process can be selective for secondary carotenoids only.

Acknowledgements The authors would like to thank Dr. Ami BenAmotz for kindly providing $D$. bardawil and would like to thank Ric de Vos for his help with the interpretation of the HPLC results. This research was financially supported by the technology foundation STW (http://www.stw.nl; project WLM.6622), which is part of the Netherlands Organization for Scientific Research (http://www.nwo.nl).

Open Access This article is distributed under the terms of the Creative Commons Attribution Noncommercial License which permits any noncommercial use, distribution, and reproduction in any medium, provided the original author(s) and source are credited.

\section{References}

Bassi R, Caffarri S (2000) Lhc proteins and the regulation of photosynthetic light harvesting function by xanthophylls. Photosynth Res 64:243-256

Bassi R, Pineau B, Dainese P, Marquardt J (1993) Carotenoid-binding proteins of photosystem II. Eur J Biochem 212:297-303

Ben-Amotz A (1996) Effect of low temperature on the stereoisomer composition of $\beta$-carotene in the halotolerant alga Dunaliella bardawil (chlorophyta). J Phycol 32:272-275

Ben-Amotz A, Avron M (1983) On the factors which determine massive $\beta$-carotene accumulation in the halotolerant alga Dunaliella bardawil. Plant Physiol 72:593-597

Ben-Amotz A, Katz A, Avron M (1982) Accumulation of $\beta$-carotene in halotolerant algae: purification and characterization of $\beta$ carotene-rich globules from Dunaliella bardawil (chlorophyceae). J Phycol 18:529-537

Ben-Amotz A, Lers A, Avron M (1988) Stereoisomers of $\beta$-carotene and phytoene in the alga Dunaliella bardawil. Plant Physiol $86: 1286-1291$

Bino RJ, de Vos CHR, Lieberman M, Hall RD, Bovy RD, Bovy A, Jonker HH, Tikunov Y, Lommen A, Moco S, Levin I (2005) The light-hyperresponsive high pigment- $2^{d g}$ mutation of tomato: alterations in the fruit metabolome. New Phytol 166:427-438

Deroche ME, Briantais JM (1974) Absorption spectra of chlorophyll forms, $\beta$-carotene and lutein in freeze-dried chloroplasts. Photochem Photobiol Sci 19:233-240

Fraser PD, Pinto MES, Holloway DE, Bramley PM (2000) Application of high-performance liquid chromatography with photodiode array detection to the metabolic profiling of plant isoprenoids. Plant J 24:551-558

Garcia-Gonzalez M, Moreno J, Manzano JC, Florencio FJ, Guerrero MG (2005) Production of Dunaliella salina biomass rich in 9-cis- $\beta$-carotene and lutein in a closed tubular photobioreactor. J Biotechnol 115:81-90

Hejazi MA, de Lamarliere C, Rocha JMS, Vermuë M, Tramper J, Wijffels RH (2002) Selective extraction of carotenoid from the alga Dunaliella salina with retention of the viability. Biotechnol Bioeng 79:29-36

Hejazi MA, Andrysiewicz E, Tramper J, Wijffels RH (2003) Effect of mixing rate on $\beta$-carotene production and extraction by Dunaliella salina in two-phase bioreactors. Biotechnol Bioeng 84:591-596

Hejazi MA, Holwerda E, Wijffels RH (2004) Milking microalga Dunaliella salina for $\beta$-carotene production in two-phase bioreactors. Biotechnol Bioeng 85:475-481

Jimenez C, Pick U (1994) Differential stereisomer compositions of $\beta$, $\beta$-carotene in thylakoids and in pigment globules in Dunaliella. J Plant Physiol 143:257-263

Jin E, Melis A (2003) Microalgal biotechnology: carotenoid production by the green algae Dunaliella salina. Biotechnol Bioprocess Eng 8:331-337

Jin E, Polle JEW, Melis A (2001) Involvement of zeaxanthin and of the $\mathrm{Cbr}$ protein in the repair of photosystem II from photo- 
inhibition in the green alga Dunaliella salina. Biochim Biophys Acta 1506:244-259

Jin E, Feth B, Melis A (2002) A mutant of the green alga Dunaliella salina constitutively accumulates zeaxanthin under all growth conditions. Biotechnol Bioeng 81:115-124

Krol M, Maxwell DP, Huner NPA (1997) Exposure of Dunaliella salina to low temperature mimics the high light-induced accumulation of carotenoids and the carotenoid binding protein (Cbr). Plant Cell Physiol 38:213-216

Lamers PP, Janssen M, de Vos RCH, Bino RJ, Wijffels RH (2008) Exploring and exploiting carotenoid accumulation in Dunaliella salina for cell-factory applications. Trends Biotechnol 26:631-638

Leon R, Martin M, Vigara J, Vilchez C, Vega JM (2003) Microalgae mediated photoproduction of $\beta$-carotene in aqueous-organic two phase systems. Biomol Eng 20:177-182

Öquist G, Samuelsson G (1980) Sequential extraction of chlorophyll from chlorophyll-protein complexes in lyophilized pea thyla- koids with solvents of differential polarity. Physiol Plant 50:5762

Skulberg OM (2004) Bioactive chemicals in microalgae. In: Richmond A (ed) Handbook of microalgal culture. Biotechnology and applied phycology. Blackwell Science, Oxford

Tardy F, Havaux M (1996) Photosynthesis, chlorophyll fluorescence, light-harvesting system and photoinhibition resistance of a zeaxanthin-accumulating mutant of Arabidopsis thaliana. J Photochem Photobiol B Biol 34:87-94

Yamamoto HY (1979) Biochemistry of the violaxanthin cycle in higher plants. Pure Appl Chem 51:639-648

Yokthongwattana K, Savchenko T, Polle JEW, Melis A (2005) Isolation and characterization of a xanthophyll-rich fraction from the thylakoid membrane of Dunaliella salina (green algae). Photochem Photobiol Sci 4:1028-1034

Zhu CJ, Lee YK (1997) Determination of biomass dry weight of marine micro-algae. J Appl Phycol 9:189-194 